\title{
COMPARISON OF OPERATION AND CLINICAL FINDINGS IN MITRAL STENOSIS AND INCOMPETENCE
}

\author{
BY \\ ALBERT VENNER AND H. E. HOLLING* \\ From the Cardiac Department and the Clinical Research Unit, Guy's Hospital
}

Received November 5, 1952

Experience gained with surgical treatment of the diseased mitral valve has increased our knowledge of its function. At operation the surgeon can observe the character and degree of the pulsation of the atrium, and on opening the atrium he can judge with his finger the size of the valve orifice, the state of the valve cusps, and whether or not a regurgitant stream can be felt. Direct measurements of the pressure within the heart chambers can be made. It is therefore possible to compare the state of the valve at operation with the findings in the examinations before operation.

In most cases of mitral stenosis selected for valvotomy it is found that the valve orifice is not more than $1.0 \times 0.5 \mathrm{~cm}$. in size. The valve cusps retain considerable flexibility as is shown by the manner in which they bulge into the atrium during ventricular systole, and, even if a regurgitant jet is felt before the commissures are divided, clinical improvement follows adequate separation of the cusps (Baker et al., 1952). In other cases with a similar sized orifice the cusps are more rigid from fibrosis and calcification, and valvotomy is difficult to achieve because of this. Even if the cusps are separated with a knife, their relative immobility prevents the valve opening, and clinical improvement does not follow.

We have had experience of a further group, also with rigid margins, but with a valve orifice appreciably larger and a palpable regurgitant stream. These cases appeared to be clearly unsuitable for valvotomy, not only because of the rigidity of the valve cusps but also because, as the stenosis was less, proportionately less improvement could be expected to follow its relief. In the cases with the largest orifices, the surgeon considered there was no stenosis and that rigid or shrunken cusps were failing to close the valve aperture during ventricular systole.

From these observations it follows that in the selection of cases for valvotomy it is important to be able to exclude those with wide orifices and rigid cusps. We have examined the records of such patients to see whether they presented any characteristic features. For the reports of the findings at operation we are indebted to Mr. R. C. Brock. Dr. Maurice Campbell and Dr. Charles Baker were the physicians in charge of these patients.

\section{MATERIAL}

We have analysed the clinical, radiological, and electrocardiographic features and the results of cardiac catheterization in the 96 cases in which at the time of analysis the valve had been explored at operation. In 61 no regurgitation had been felt, and all these were found to have an orifice of less than $1.0 \times 0.5 \mathrm{~cm}$.: these we have called cases of pure mitral stenosis. The remainder had a palpable regurgitant stream; 26 had small orifices of similar size to the cases of pure mitral stenosis; 9 had rigid valve orifices greater in size than $1.25 \times 0.75 \mathrm{~cm}$. The group of 26 intermediate cases have been put on one side in order to throw into contrast any distinguishing features between the group with pure mitral stenosis and the group with comparatively wide, rigid valve orifices, and palpable regurgitation.

\footnotetext{
* Work undertaken on behalf of the Medical Research Council.
} 
TABLE I

The Size of the Mitral Orifice Iin Mitral InCOMPetence

\begin{tabular}{|c|c|c|c|}
\hline Case No. & $\begin{array}{l}\text { Size of orifice } \\
\text { (in } \mathrm{cm} \text {.) }\end{array}$ & Case No. & $\begin{array}{l}\text { Size of orifice } \\
\text { (in } \mathrm{cm} \text {.) }\end{array}$ \\
\hline $\begin{array}{l}\text { G } 76 \\
\text { G } 57 \\
\text { G } 77 \\
\text { G } 53 \\
\text { G } 36\end{array}$ & $\begin{array}{l}1.25 \times 0.75 \\
1.25 \times 0.75 \\
1.75 \times 1.0 \\
2.0 \times 1.0 \\
2.5 \times 10\end{array}$ & $\begin{array}{l}\text { G } 73 \\
\text { G } 83 \\
\text { G aa } \\
\text { G } 116\end{array}$ & $\begin{array}{l}3.0 \times 1.5 \\
4.0 \times 1.5 \\
4.0 \times 2.5 \\
3.0 \times 1.5\end{array}$ \\
\hline
\end{tabular}

Of the 9 cases with wide, rigid orifices four had been diagnosed as having predominant stenosis. In Cases G 57, G 73, G 116, and G 77 considerable mitral regurgitation had been suspected and it was intended, if this was confirmed, to insert a pericardial flap to lessen the degree of regurgitation. The ninth (Case G aa, reported elsewhere by Venner, 1953) had been diagnosed as mitral incompetence together with constrictive pericarditis, and the state of the valve was determined at operation for pericardectomy.

\section{MeTHODS}

Pressure records were made with an electrical condenser manometer (Peterson, 1949). When recording pulmonary capillary pressure the catheter was advanced along the pulmonary artery until it reached a branch small enough to be occluded by the cather tip. The pressure then recorded was believed to be that in the pulmonary capillaries, or more probably the pulmonary veins (Lagerlöf and Werkö, 1949; Hellems, Dexter et al., 1949).

Fig. 1 shows a pulmonary capillary pulse record obtained in pure mitral stenosis; on it is superimposed the pulmonary artery pulse taken from the same patient. In the pulmonary capillary pulse two pressure waves to each cardiac cycle can be distinguished; they have been termed the $\mathrm{A}$

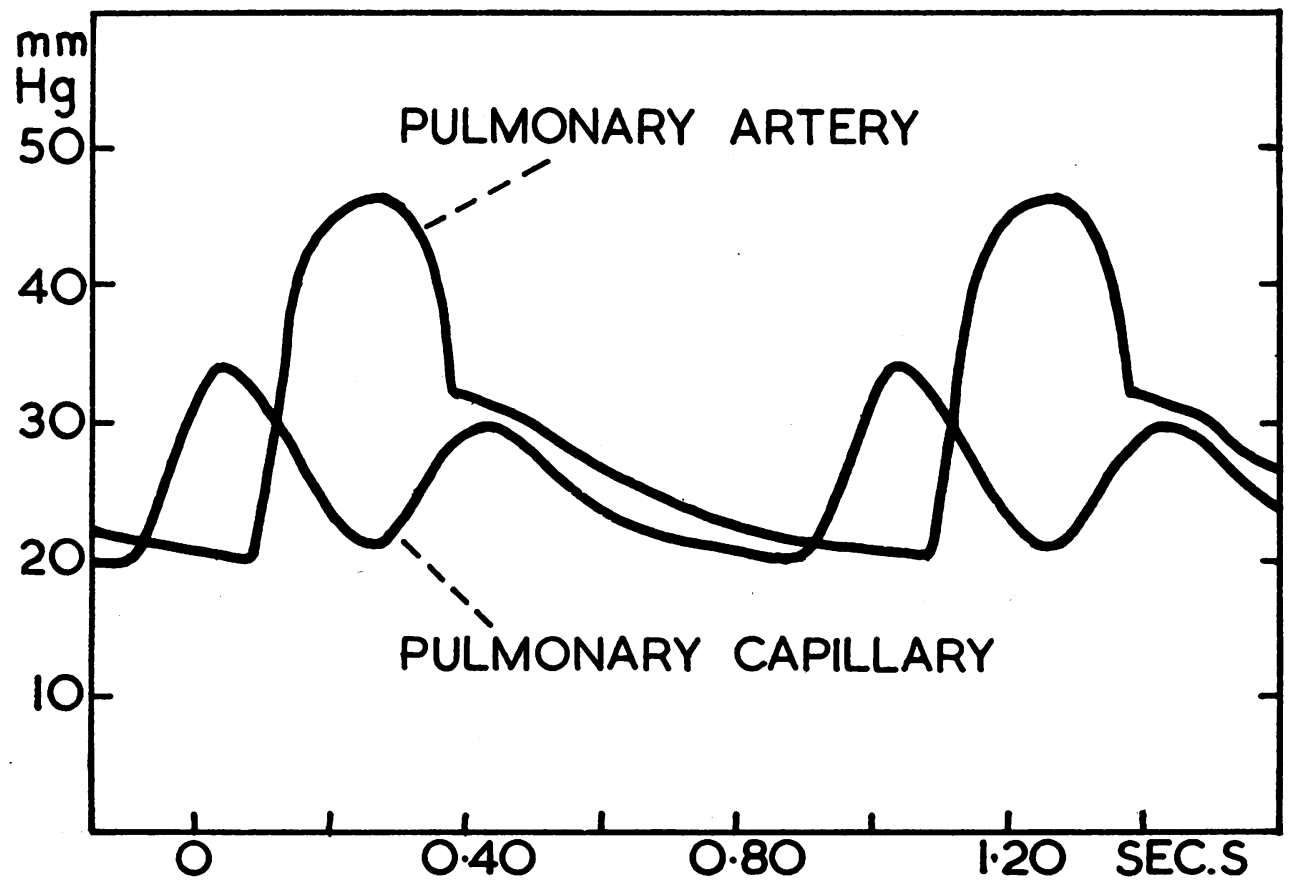

Fig. 1.-Pulmonary arterial and pulmonary capillary tracings from a case of mitral stenosis. 
and the $\mathrm{V}$ wave. The $\mathrm{A}$ wave is so called because it appears to be due to atrial systole and is not seen when there is auricular fibrillation.

In only about half our cases have we been able to obtain a satisfactory pulmonary capillary record. In those with large hearts the catheter may make a wide loop in passing through the heart, and insufficient length is left for the tip to be advanced into a small vessel. In some cases a damped pulmonary artery pulse is recorded, even though the catheter tip seems to be wedged in a small vessel. When the characteristic $A$ and $V$ waves shown in Fig. 1 are present the record can be accepted as a pulmonary capillary pressure pulse. In cases of auricular fibrillation where the A wave is absent we have adopted the following criteria. There should be the feeling, particularly on withdrawal, that the catheter is wedged in the vessel in which it lies; aspiration of blood from the catheter should yield either arterialized blood or no sample at all; and the main pulse wave of the pulmonary capillary should be delayed compared with the pulse wave of the pulmonary artery. Often, however, the record is obscured by artefact and is unsuitable for analysis.

In most cases the records were taken in quick succession through the double lumen catheter using a single manometer. From such records the timing of the peak of the $\mathrm{V}$ wave relative to the dicrotic notch of the pulmonary artery pulse was determined by measurement from the simultaneous electrocardiogram, choosing sections with an equal heart rate. Measurements were made from at least five beats, and the mean of these recorded. More recently, simultaneous pulmonary capillary and pulmonary artery records have been made with a double lumen catheter, using two manometers.

Left atrial and ventricular tracings were recorded at operation by puncture with a 21-gauge needle connected to the manometer by a metre of hardened plastic tubing of $1.4 \mathrm{~mm}$. internal bore. Until two manometers became available we recorded the two tracings in quick succession and later superimposed them by measurement from the simultaneous electrocardiogram.

\section{FINDINGS}

History and Symptoms. There were no significant differences of age and sex incidence, or duration of severity and type of symptoms between the group of 9 cases with wider mitral orifices and those with pure mitral stenosis. Six of the nine gave a history of rheumatic fever, two of frequent hæmoptyses, four of attacks of paroxysmal dyspnœa, and six of congestive heart failure. Eight of the nine cases had auricular fibrillation.

The Apex Impulse. The normal apex impulse has a short thrusting character. With cardiac hypertrophy this quality usually becomes more obvious, giving a lifting impulse. When the left ventricle is predominantly and markedly involved in the hypertrophy the apex impulse has a sustained heaving quality. In contrast, in mitral stenosis the apex has a short tapping quality. A note had been made on the character of the apical impulse in 41 of the 61 cases of pure mitral stenosis. In two of these it was described as normal Five cases were said to have a lifting impulse at the apex, but they had significant aortic valve disease in addition to their mitral stenosis. In the others, the impulse was described as tapping. Of the 9 cases with wider orifices, no record was available in one: the impulse described as tapping in two only while in six it was described as lifting, and in only two of these could this be ascribed to aortic valve disease.

Auscultation. With the exception of the case of constrictive pericarditis all the patients had a mid-diastolic murmur. In one at least (G 116) this was of very short duration.

All systolic murmurs appeared to start with the first sound and occupied the major part or all of systole, and there were no examples of short or late systolic murmurs. They were graded according to their loudness by Levine's (1945) method (Table II). Of the 61 cases subsequently found to have no palpable regurgitation, 13 had an apical systolic murmur. All those with wide mitral orifices had an apical systolic murmur, though in one it was only of Grade II intensity. The quality of the murmur did not serve to distinguish the two groups; in both, all Grade IV murmurs were described as harsh and the Grade II and III murmurs were described as either harsh or blowing. 
TABLE II

Apical Systolic Murmur in Mitral Valve Disease

\begin{tabular}{cc|c|c|c}
\hline $\begin{array}{c}\text { State and function of } \\
\text { mitral valve at operation }\end{array}$ & \multicolumn{2}{|c}{$\begin{array}{c}\text { Intensity of murmurs } \\
\text { (Levine's classification) }\end{array}$} \\
\hline \multirow{6}{*}{61 cases of mitral stenosis } & $\ldots$ & $\begin{array}{c}\text { Grade IV } \\
\text { or more }\end{array}$ & Grade III & $\begin{array}{c}\text { Grade II } \\
\text { or less }\end{array}$ \\
\cline { 2 - 5 } & $\begin{array}{c}1 \\
\text { (with thrill) }\end{array}$ & 6 & 6 \\
\hline 8 cases with regurgitation &.. & $\begin{array}{c}4 \\
(2 \text { with thrill) }\end{array}$ & 3 & 1 \\
\hline
\end{tabular}

In three of the cases with wide mitral orifices the first heart sound showed the abrupt quality associated with mitral stenosis, but the opening snap was absent. An opening snap was heard in Case $\mathbf{G} 73$ with the third largest mitral orifice. Triple rhythm, due to the addition of a third heart sound, was heard in three cases, but not in any of those with pure mitral stenosis.

Size of Heart. The mean cardiothoracic ratio of the 61 cases with pure mitral stenosis was 56 (range 46 to 71), whereas in the 9 with wider mitral orifices it was 64 (range 53 to 76).

Left Ventricular Hypertrophy. In the 9 patients unsuitable for valvotomy electrocardiographic records showed no evidence of ventricular hypertrophy in 4; right ventricular hypertrophy in 3 ; and in the 2 others, who had aortic valve disease also, one showed left ventricular hypertrophy and the other both left and right ventricular hypertrophy. Cardiographic evidence of left ventricular hypertrophy was not therefore a diagnostic feature; nor was the absence of right ventricular hypertrophy, for it was absent also in one-fifth of those with pure mitral stenosis without aortic valve disease.

At screening, enlargement of the left ventricle was remarked in only 4 of the 9 unsuitable for valvotomy, and in 3 of these a clinical diagnosis of aortic valve disease had been made.

Systolic Expansion of the Left Atrium. At fluoroscopy the 9 cases with wide mitral orifices showed enlargement of the left atrium, but not more than most of those with small orifices. In only two, G aa and G 116 (Table I), was systolic expansion of the left atrium seen whereas " expansile pulsation " was recorded in 5 of the cases of pure mitral stenosis. In Case $\mathbf{G}$ aa pulsation was seen in both anterior-posterior and right oblique views.

Findings at Catheterization. Table III shows the cardiac indices, pulmonary artery and pulmonary capillary pressures in those with wide rigid orifices. The mean of the values obtained does not differ significantly from that of the cases of pure mitral stenosis with a similar degree of disability.

TABLE III

\begin{tabular}{|c|c|c|c|c|}
\hline & & $\begin{array}{l}\text { Pulmonary artery } \\
\text { pressure (mm. Hg.) }\end{array}$ & $\begin{array}{l}\text { Pulmonary capillary } \\
\text { pressure }(\mathrm{mm} . \mathrm{Hg})\end{array}$ & $\begin{array}{l}\text { Cardiac index } \\
\text { (1./sq.m./min.) }\end{array}$ \\
\hline $\begin{array}{l}\text { Pure mitral stenosis } \\
\text { Mitral regurgitation }\end{array}$ & $\because$ & $\begin{array}{ll}52 & (41) \\
52 & (9)\end{array}$ & $\begin{array}{ll}25 & (27) \\
26 & (5)\end{array}$ & $\begin{array}{rr}2.0 & (40) \\
2.0 & (8)\end{array}$ \\
\hline
\end{tabular}

The figures in parentheses refer to the number of patients.

Pulmonary Capillary Tracings. Lagerlof and Werko (1949) state that the V wave is taller and broader when mitral incompetence is present. Soulié states that pulmonary capillary curves provide written and objective proof of the presence of mitral regurgitation, for he finds that when he has diagnosed this condition, whether auricular fibrillation is present or not, the peak of the $\mathrm{V}$ wave occurs 0.04 to 0.08 seconds before the end of the period of pulmonary ejection, whereas in mitral 
stenosis the summit of the V wave occurs immediately after this period (Soulié et. al., 1951). The dicrotic notch of the pulmonary artery tracing is taken as the end of the ejection period. In our cases the summit of the $\mathrm{V}$ wave occurred after the dicrotic notch of the pulmonary artery tracing in those with pure mitral stenosis and those with wide orifices alike. Neither did the height of the $\mathrm{V}$ wave serve to distinguish the two groups. The results obtained from our measurements of the V wave in 12 cases with pure mitral stenosis and 5 with wide mitral orifices are summarized in Table IV.

TABLE IV

Height and Timing of V Wave in the Pulmonary Capillary Tracing in Cases of Mrtral Valve Disease

\begin{tabular}{|c|c|c|c|c|}
\hline \multirow[t]{2}{*}{ Diagnosis (confirmed at operation) } & \multicolumn{2}{|c|}{$\begin{array}{l}\text { Height of V wave } \\
\text { (mm. Hg) }\end{array}$} & \multicolumn{2}{|c|}{$\begin{array}{l}\text { Time of peak of } \mathrm{V} \text { wave } \\
\text { after dicrotic notch of } \\
\text { pulmonary artery } \\
\text { tracing (seconds) }\end{array}$} \\
\hline & Mean & Range & Mean & Range \\
\hline $\begin{array}{l}12 \text { cases with no palpable regurgitation } \\
5 \text { cases with palpable regurgitation } \\
\text { (Cases G aa, G 53, G 57, G 77, } \\
\text { G 116)* } \\
\text {.. }\end{array}$ & 8 & $\begin{array}{l}3-30 \\
9-32\end{array}$ & 0.04 & $\begin{array}{l}0.01 \text { to } 0.12 \\
0.02 \text { to } 0.06\end{array}$ \\
\hline
\end{tabular}

* All cases with auricular fibrillation.

Left Atrial Pressure Tracings. In no case could systolic expansion of the left atrium be seen by those present at operation, or felt by the surgeon; not even in cases $G$ aa and $G$ 166, in whom it had been seen at fluoroscopy. We were able to record pressure pulses from the left atrium and ventricle in most of the patients and in all the nine with wide rigid orifices. Fig. 2 shows representative tracings from three with pure mitral stenosis and auricular fibrillation, for comparison with those obtained from three others with a wide mitral orifice. In Fig. 3 are given the maximum pressures recorded in pure mitral stenosis and in the 9 with wide mitral orifices. It will be seen that the rise in pressure in the left atrium during ventricular systole was no greater in the group with wide mitral orifices, and presumably marked mitral regurgitation, than in the group with pure mitral stenosis. Wynn et al. (1952) obtained similar results.

\section{Discussion}

Where there was a wide rigid orifice the apical systolic murmur was loud, and the surgeon did not encounter such an orifice in a patient in whom no systolic murmur has been heard. However, a loud murmur, and even a thrill, is not a certain indication that the valve is unsuitable for valvotomy, for one case had a Grade IV murmur and a thrill and yet proved to have a small orifice with supple valves and no regurgitation. In an unselected series of cases of mitral stenosis the proportion with a loud systolic murmur, yet suitable for valvotomy, would be higher, for in the past such a murmur has been a point against selection for valvotomy. We have not found that any particular character of the murmur is associated with those unsuitable for valvotomy. The occurrence of a third heart sound would seem to be a point against advising valvotomy, but this sign is recognized with difficulty when there is a mid-diastolic murmur, and such a murmur is necessarily present in a case being considered for mitral valvotomy.

Absence of a tapping quality of the apex impulse would appear to be an indication that the valve is unsuitable for valvotomy. According to Logan and Turner (1952) the slapping quality of the first heart sound that is associated with mitral stenosis is faint or absent in cases of predominant incompetence. Though no note was made on this in most of our cases, it is a point that we have recognized as being of value. 


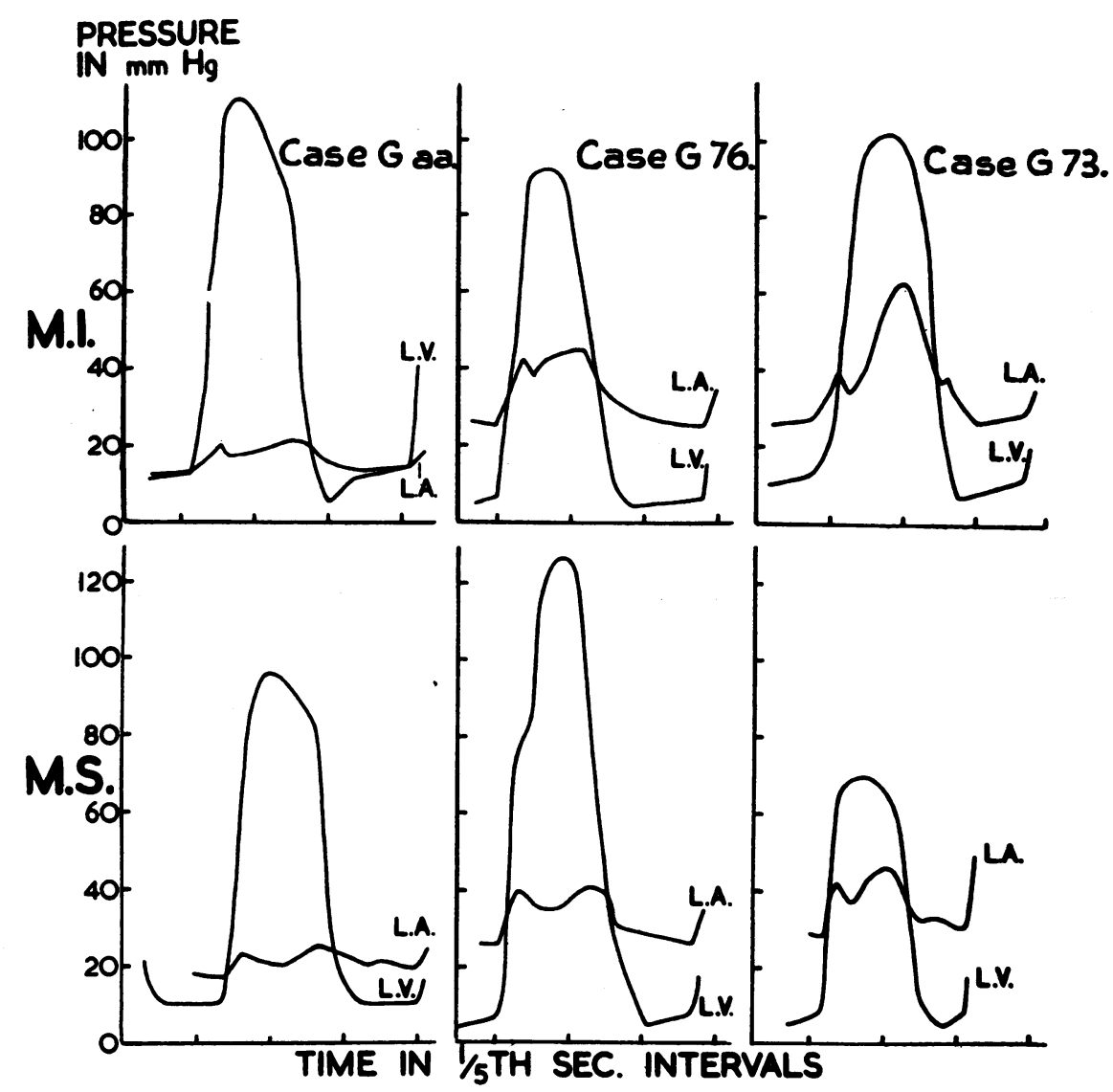

FIG. 2.-Left ventricular and left atrial pulse tracings from three cases with palpable regurgitation and orifices greater than $1.25 \times 0.75 \mathrm{~cm}$. (M.I.), and three cases of mitral stenosis with no palpable regurgitation (M.S.). All cases had auricular fibrillation.

Expansile pulsation of the atrium on fluoroscopic examination has been found in only two of the cases with a rigidly open orifice, and enlargement of the left ventricle in only four (and in three of these the ventricular enlargement might have been due to coexisting aortic valve disease). A retrograde pressure wave from the contracting left ventricle was not detectable in the pulmonary capillary tracings, nor even in those from the left atrium. Thus the signs that are believed to result from the regurgitation of a considerable volume of blood were not in practice found to be a feature of this group.

Our results show that investigation by radiological methods and cardiac catheterization failed to distinguish the cases with wide, rigid valve orifices, but some help was afforded by palpation and auscultation. The recognition of these before operation is difficult and the physician must expect to have his assessment occasionally upset at operation. If he rejects all those with a systolic murmur this will be less likely to happen, but some will be unnecessarily rejected. If the condition of the mitral valve is in doubt in a patient for whom surgical treatment is otherwise indicated, it is justifiable to perform a surgical exploration of the valve.

Mitral regurgitation. When the knowledge of the effects of rheumatic heart disease on the function of the mitral valves was based on the appearance of the valve post mortem, it was presumed that considerable quantities of blood regurgitated through the diseased mitral valve with 


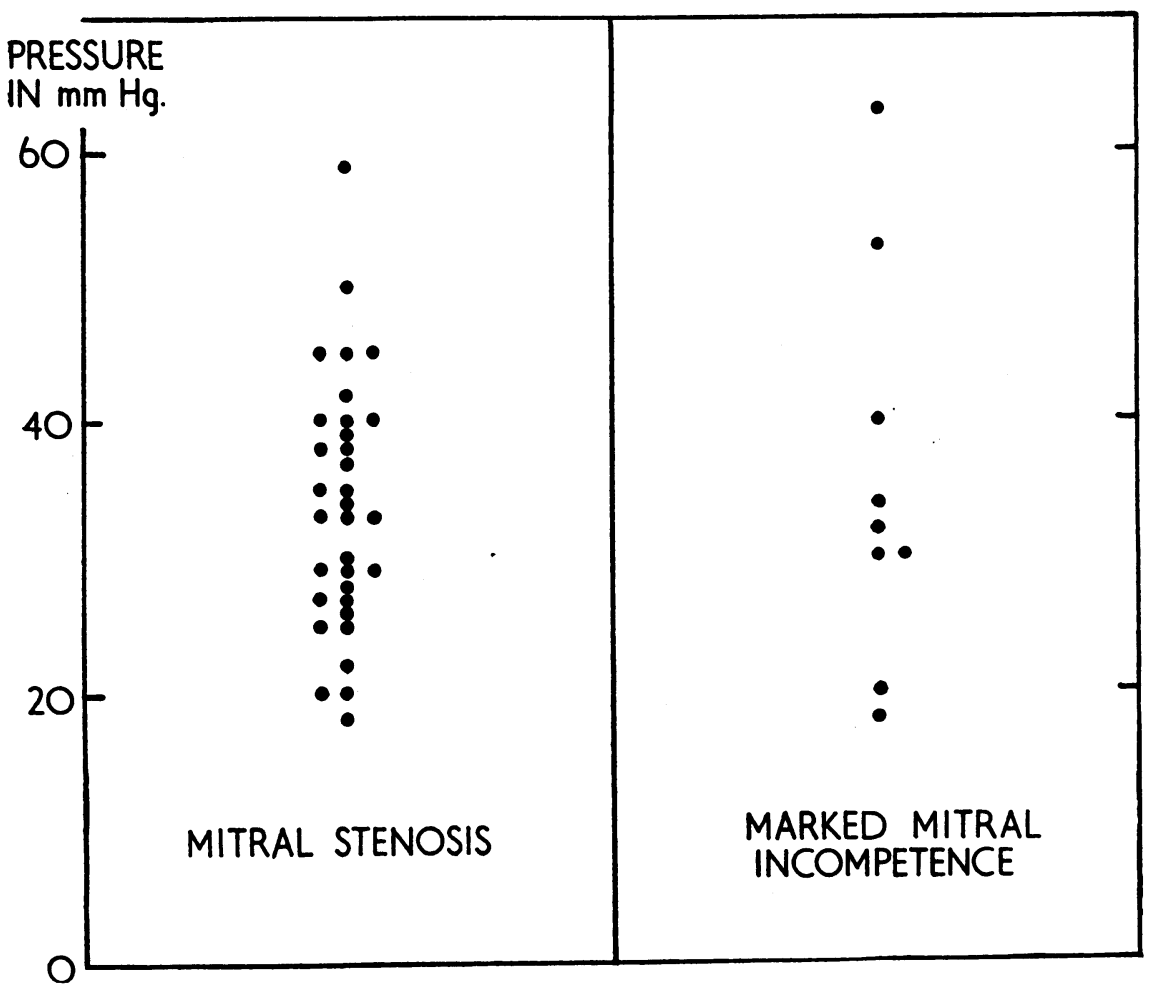

Fig. 3.-Maximum pressure in the left atrium in cases of mitral stenosis (left) and the cases of marked mitral incompetence (right).

a wide, rigid orifice. Gorlin (1952) has put forward an ingenious method of calculating the volume of regurgitation and finds that the volume is such that the rigid mitral orifice is obstructed during ventricular systole: the method, however, involves a number of assumptions and no method of checking the results exists. Our findings indicate that the volume of blood regurgitated is smaller than had been thought. Though the surgeon can feel a regurgitant stream in cases with a wide, rigid orifice, he can neither see nor feel a systolic increase in the volume of the left atrium. We also have been unable to demonstrate a greater systolic increase in atrial pressure than may occur in pure mitral stenosis. It might be objected that this is because conditions at operation are abnormal. In the examination of these cases, before operation, however, expansile pulsation of the left atrium has not been detected, nor in the pulmonary capillary tracing have we been able to show a characteristic wave of high pressure coinciding with ventricular systole.

Studies on the form of the systolic heart (Quain, 1929) suggest how the mitral orifice may be guarded from the full effects of the ventricular pressure. "In the contracted left ventricle . . . the two papillary muscles come into contact with one another and the lateral wall of the ventricle comes into contact with the papillary muscles, so that the interpapillary space and the 'inflowing' part of the ventricle, with the exception of a small space behind the posterior cusp of the mitral valve and the heart wall are obliterated." Fig. 4 (after Quain) shows the anatomical relationship of the structures concerned, and indicates how the inflow portion of the ventricle may be obstructed during ventricular systole.

All these observations indicate that the volume of blood regurgitated through a wide and rigid mitral valve is small in comparison with the capacity of the left atrium and pulmonary veins. 


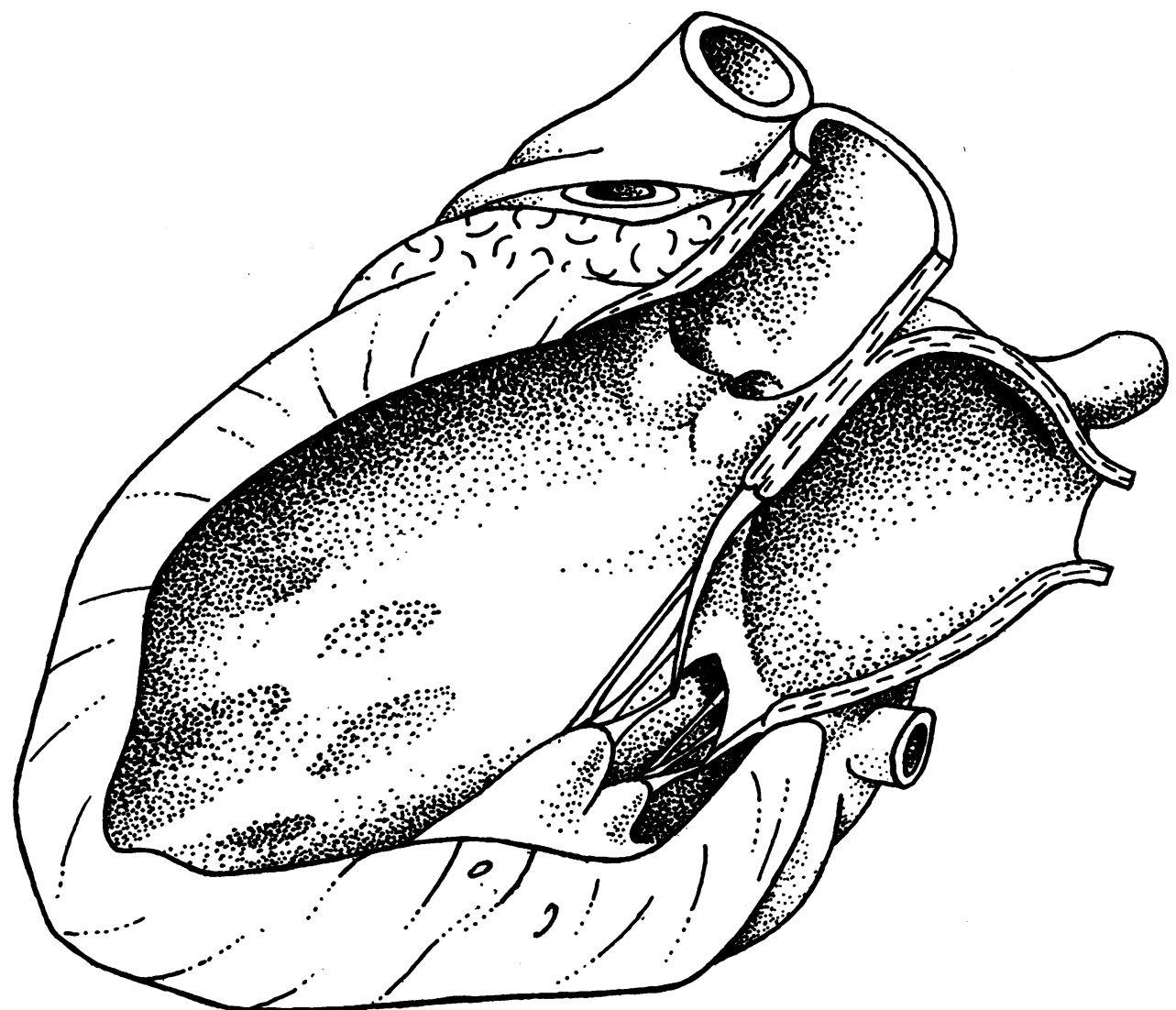

FIG. 4. - Section of heart through mitral valve (after Quain) to show relationship of mitral orifice to the cavity of the left ventricle.

\section{SUMmaRY AND ConClusions}

The valves of 96 patients with mitral disease were examined at operation; 61 of them were found to have severe mitral stenosis and no palpable regurgitant stream and were suitable for valvotomy, 9 were found to have larger rigid orifices and a regurgitant stream and were unsuitable for valvotomy. The findings in these two groups before operation are compared. Twenty-six cases with intermediate degrees of stenosis and regurgitation were not used in this comparison.

A " lifting" apical impulse was not found in any of the cases with mitral stenosis alone, whereas it was found in six of eight with wide rigid mitral orifices. All the latter had a loud systolic murmur, but this sign was often present in pure mitral stenosis also. The two groups could not be clearly separated on other clinical findings, nor did electrocardiography, radiology, or cardiac catheterization accomplish this.

The 9 cases with rigidly open valve orifices would readily be classed on pathological examination as examples of mitral incompetence; moreover, the surgeon felt a regurgitant jet of blood in them. The exposed atrium, however, did not show systolic expansion, nor was the systolic rise of atrial pressure greater than that recorded in pure mitral stenosis. These findings indicate that the volume of regurgitant blood is small in comparison with the volume of the left atrium and pulmonary veins. Supporting evidence for this statement is given by the absence of systolic expansion of the left atrium on fluoroscopy, and the absence of differences in the $\mathrm{V}$ wave of the pulmonary capillary tracings in the two groups. The explanation is offered that free regurgitation does not necessarily occur through a valve with a rigidly open orifice, because it is guarded during ventricular systole by apposition of the papillary muscles and the ventricular wall. 
Dr. David Verel played a large part in the development of the technique used for recording of pressure pulses. The valuable technical assistance of Mr. J. O'Halloran and Mr. P. Sarbinowski is also acknowledged.

\section{REFERENCES}

Baker, C., Brock, R. C., Campbell, M., and Wood, P. (1952). Brit. med. J., 1, 1043.

Gorlin, R., and Dexter, L. (1952). Amer. Heart J., 43, 188.

Hellems, H. K., Haynes, F. W., and Dexter, L. (1949). J. App. Physiol., $2,24$.

Lagerlöf, H., and Werkö, L. (1949). Scand. J. Clin. Lab. Invest., 1, 147.

Levine, S. A. (1945). Clinical Heart Disease. 3rd ed. (rev.). Philadelphia and London.

Logan, A., and Turner, R. (1952). Lancet, $2,593$.

Peterson, L. H., Dripps, R. D., and Risman, E. C. (1949). Amer. Heart. J., 37, 771.

Quain's Anatomy (1929). The Heart. Vol. IV. 11th ed. London.

Soulié, P., Carlotti, J., Sicot, J. R., and Joly, F. (1951). Sem. Hop. Paris, 27, 2627.

Venner, A. (1953). To be published.

Wynn, A., Matthews, M.B., McMillan, I. K. R., and Daley R. (1952). Lancet, 2, 216. 